\title{
Linguagens de Pertencimento: modalidades de intermediação, práticas culturais e identitárias
}

\begin{abstract}
"We have the notion of identity as conlradictory, as composed of more than one discourse, as composed always across the silences of the other, as written in and through ambivalence and desire. These are extremely important ways of trying to think an identity which is not a sealed or closed totality".
\end{abstract}

(Stuart Hall, Old and New Identities, Old and New Ethnicities)

Resumo: $\mathrm{O}$ artigo trata da disseminação do Rap Nacional (seu impacto social, no papel da política lírica de um discurso politizado em torno da interação social e do cotidiano) enquanto meio de produção cultural, objeto de consumo imerso no contexto da cultura hip-hop. Reafirma a importância como projeto artístico de resistência ao sistema hierárquico de poder e prestígio, como componente musical integrado no fluxo global de produtos, idéias, estilos, ou seja, enquanto linguagem cultural e consumível.

O termo hip-hop na verdade

Rosana Martins é mestre e doutoranda em Ciências da Comunicação pela ECA-USP, professora da Faculdade de Belas Artes de São Paulo e pesquisadora do grupo SOMA- Som e Antropologia, da Faculdade de Filosofia, Letras e ciências Humanas, Departamento de Antropologia. aquele que coloca a música para dançar; a dança break, para aqueles que se expressam por meio de movimentos da dança; o grafite, as artes plásticas e a arte visual no hip-hop.

A existência das subculturas juvenis acabam dando margem para novas leituras, freqüentemente tidas como não-natural, em formatos que levam a transgressão de códigos comportamentais, quebras de leis, consciência de classe, enfim, abrindo continuamente superfícies para se pensar uma nova normalização da sociedade (Hebdige, 1988). O hip-hop emergiria de experiências e práticas dos jovens em desvantagem econômica, participantes de uma cultura distinta da ordem dominante marcada por uma série de práticas integradas incluindo a dança, a música e arte visual com o objetivo de disponibilizar espaços para a interação e comunicação de grupos marginalizados, um fórum pelos quais pudessem rever o significado de ser jovem e negro (Rose, 1994).

A construção poético-musical do rap no Brasil - como um dos principais pilares de um movimento cultural e artístico, o hip-hop -, tem se esforçado na tentativa de denunciar e buscar soluções para fatores que tendem a paralisar a pretensão de progresso neste país tais como, a pobreza, a violência urbana, a violência policial, a discriminação racial, o resgate da auto-estima dos afro-brasileiros, as altas taxas de desemprego, de desigualdade na distribuição da renda e no uso das drogas, a falência da rede educacional, chacinas, dentre outros 
(Andrade, 1999). É nessa visão opressiva que o Rap Nacional vem retratando a realidade social numa luta pela consolidação das bases democráticas.

Numa escala global o rap vem se assentando num discurso (lírico e musical) afirmativo, reflexivo e narrativo da representação de si próprio, das suas experiências e das suas convicções. Isto o torna uma fórmula acessível de prática intensiva da identidade. Encarado como um dos elementos das estratégias culturais da autodefinição e automanutenção, um tipo de subsistência ideológicoidentitária sobre a relação que um indivíduo estabelece com o mundo ou, melhor, o modo do being in the world.

Nesse contexto, para que possamos compreender os significados incorporados nas narrativas musicais dos grupos de rap, anteriormente analisados, buscamos considerar a noção de pertencimento público como vinculada à idéia de socialização e redefinida no papel simbólico da inclusão - espaço onde cada individuo é levado a se ver como um indivíduo social e a fazer suas normas de pertencimento social, fazer parte, inserir-se, ser membro.

Certamente, a questão mais complexa do atual cenário público encontra-se centrado nas ambivalências por que passam as configurações societárias em meio a desestabilização, ao desmanche das referências de um mundo comum (Martins, 2000). Uma erosão que vem se realizando na prática, desestruturando formas de vida e obstruindo perspectivas de futuro porque sujeito ao imponderável; isso que a socióloga Vera da Silva Telles (2001) chama de "violência costumeira" vem aumentando nos bairros pauperizados da cidade de São Paulo, no caso, encontra-se vinculada a uma modernização selvagem processando exclusões e segmentações, bloqueando perspectivas de vida e descredenciando experiências, formas de ser e de fazer.
Na verdade, o indivíduo já não tem como se reconhecer nas relações sociais da vida cotidiana apenas na condição da sua própria alteridade, não mais como pessoa inteira, singular ou como indivíduo da própria unidade de ação. Para Hannah Arendt o "mundo no qual transcorre a vida activa consiste em coisas produzidas pelas atividades humanas; mas, constantemente as coisas que devem sua existência exclusivamente aos homens também condicionam os seus autores humanos" (1999, p. 17). Cada vez mais, encontra-se em processamento o campo da objetividade do mundo cuja identidade do ser continuamente perde a sua capacidade de compreender o estranhamento e de lidar com ele.

Percebe-se que no Brasil a desigualdade social se dá não apenas pela péssima distribuição de renda do país, mas também pela distribuição desigual de conhecimentos sobre os direitos do cidadão e de acesso à Justiça. A rigor, as diferenças sociais acabam sendo traduzidas, ora na figura do subalterno que tem como dever a sua obediência cega, ora no papel do inferior aquele merecedor da tutela, da proteção, mas jamais dos direitos.

Em seu estudo, Telles (2001) descreve como a pobreza no Brasil é freqüentemente apresentada como foco de desordem moral, de incivilidade que descredencia os pobres de ser sujeito de direitos, outrora sacramentados pela norma legal, pelo discurso jurídico em nome das leis universais, do conhecer e se reconhecer nas diferenças, mas que na prática real não se realizam como código e regra de conduta. De acordo com a autora, o não-reconhecimento do outro como sujeito de interesses e aspirações representa nada mais do que uma forma de sociabilidade que por hora não se completa, porque regida por uma lógica de anulação do outro como identidade. Como seria de se esperar, os habitantes dos espaços empobrecidos das grandes metrópoles brasileiras são tidos como marginais, ou seja, tudo aquilo que a sociedade considera como impróprio (Caldeira, 2000). 
Resta lembrar, ainda, que a pobreza inferiorizada e transformada em natureza, vista como resíduo que escapou a potência civilizadora da modernização tende a aparecer na sociedade brasileira sempre como sinal de atraso de um legado passado que acabou sendo transmitido pelo presente e que envergonha um país que cresceu acostumado a pensar ser "o país do futuro". Na certa, a pobreza incomoda mostrando o avesso do tão sonhado país que se quer moderno e que se espelha na miragem projetada nas luzes do Primeiro Mundo.

$\mathrm{O}$ caráter racionalizador do capitalismo manifesta-se diretamente na dominação absoluta do dinheiro como função calculativa regulando a relação social e individual e na busca do dinheiro como um fim em si - esse ideal cognitivo concebe o mundo como um imenso problema aritmético, coisas como um sistema de números, um símbolo da autoalienação humana na medida em que reduz todas as qualidades humanas a valores quantitativos de troca (Simmel, 1990).

Partindo do pressuposto de que o mundo vivido tornou-se colonizado, o mundo contemporâneo se mostra povoado de simulações, fetiches autonomizados, dogmas isentos de tensão e aura do real, operando numa neutralização dos sentidos, lançando ao vazio todas as diferenças (Baudrillard, 1995). Diante disso, temos a proliferação de novas posições que justamente traz as marcas do consumo afirmadas no cenário urbano contemporâneo como fundamentais para a compreensão da dinâmica cultural das cidades, transformando num novo modo de vida.

O consumo torna-se não uma função de satisfação individual harmoniosa mas, ao contrário, uma infinita atividade social que a totalidade do sistema de produção produz, um sistema de necessidades que são racionalizadas, homogeneizadas, sistematizadas e hierarquizadas, um modelo de atividade social que por sua vez insere o indivíduo na sociedade de consumo conforme comportamento socialmente normativo, absolutamente condizente ao fato de que este é um membro dessa sociedade.

Como lógica social, "o sistema" apresenta-se simultaneamente como moralidade (um sistema de valores ideológicos) e um sistema de comunicação. Pode-se dizer que a mercantilização estandardizada da vida cotidiana constitui hoje um dos principais cânones de localização do próprio indivíduo no processo social, à medida que o consumo é visto como sinônimo de "real" existência e a identidade passa, então, a ser formada e transformada continuamente pelos sistemas culturais mundializados que nos rodeiam, fazendo surgir novas identidades e fragmentando o indivíduo moderno até aqui visto como um sujeito unificado (Hall, 2000).

Ao que parece, no mercado são colocados a disposição juntos diferenciados elementos do "identikit" do eu numa ampla gama de identidades que podem ser usados diferentemente, isto é, que produzem resultados diferentes uns dos outros e que são assim personalizados, feitos sob medida para melhor atender às exigências da individualidade como parte de um estilo de vida especial, de modo que o consumidor em perspectiva possa conscientemente adquirir símbolos da auto-identidade que gostaria de possuir (Bauman, 1998). Dessa maneira, a cultura submete-se a uma nova cultura - a cultura do consumo.

Trata-se, portanto, da crescente despersonalização dos indivíduos e a forte tendência à uniformidade comportamental o que quer dizer, sob o ponto de vista de David Riesman (Caldas, 2001), que o cidadão moderno pauta seu comportamento de acordo com a conduta dos outros abandonando qualquer tipo de iniciativa pessoal e, assim, despersonalizado ele dispõe-se a seguir qualquer decisão tomada pela sociedade.

Nesse âmbito, o Rap Nacional procura a seu modo desafiar a fragmentação deixada pelo establishment, não obstante, circunscrevendo uma 
forma de autoconhecimento e (re)ação dos jovens da periferia de todo o Brasil (já que a cultura hip-hop encontra-se espalhada por todo o território nacional) aos processos massificadores que atingem o mundo contemporâneo, no qual cada um é apenas aquilo que qualquer outro pode substituir, uma coisa fủngível.

Para Brake (1985), os movimentos juvenis contemporâneos podem ser melhor compreendidos por grupos em posição estrutural subordinada em resposta ao sistema dominante de significado e que reflete no esforço de resolver as contradições estruturais que surgem no contexto social mais amplo. Significativamente, a identificação da juventude dos bairros periféricos com as músicas tem sido imediata porque narram situações reais por eles vividas.

Afinal, o Rap Nacional não apenas fala da dura realidade das ruas, mas fala na linguagem da periferia, de uma coletividade que se apresenta discursivamente e argumentativamente num espaço público de forma aberta e racional que ganha sua expressão no âmbito da vida social na composição de seus interesses, vontades e pretensões.

As seguintes reelaborações como "quebrada", "paga-pau”, "mano", "boy", "atitude", "procedê", entre outros, são linguagens das ruas periféricas que invadem a cena poética e se tomam recursos na resolução das questões criadas pelas imagens que nos remetem diretamente ao universo vivido, isto é, tornando-se parte integrante da estética rap, gerando identificações como parte de um diálogo comum (Silva, 1998). É dessa maneira, portanto, que o Rap Nacional reafirma visões de mundo, posições engajadas dentro das quais os indivíduos desenvolvem a publicidade de sua ação social expressando e questionando os valores instituídos socialmente numa leitura crítica com base na reversibilidade do modo de ser desta sociedade.

Se outrora as identidades modernas eram territoriais e quase sempre monolinguísticas consolidando na subordinação de regiões e etnias dentro de uma nação, opondo-o a outras nações; por outro lado, as identidades pós-modernas aparecem como transterritoriais e multilinguísticas, ou seja, ordenam-se no theatrum mundi menos pela lógica dos Estados do que o mercado mediante a comunicação tecnológica da produção industrial de cultura do consumo segmentado dos bens, cuja identidade passa a ser concebida por um repertório fragmentado de minipapéis mais do que como núcleo definido pela família, pelo bairro, pela cidade, pela nação ou por qualquer um desses enquadramentos em declínio (Canclini, 1999). O que quer dizer, senão que num tempo de fraturas, heterogeneidades, segmentações dentro de cada nação e comunicações fluidas marcadas por setores de redes internacionais, operam-se condensações, organizam-se outras formas de socialização mais ou menos efêmeras e de acesso aos bens de consumo brindados por dezenas de milhares de jovens que comungam valores em correspondência a incapacidade das macropolíticas sociais e culturais em dar respostas totalizadoras ao corpo social - aquilo que faz de cada um, um elemento do conjunto global, isto é, de todos participarem como soma não como partes.

Em meio a essas constelações heterogêneas encontramos códigos que nos unificam ou que ao menos permitem que nos entendamos. Esses códigos compartilhados são cada vez menos os da etnia, da classe ou da nação em que nascemos. Comprar um determinado vestuário, por exemplo, passa a ser quase a condição de circulação no espaço público, gerando uma identificação valorizada que assume papel importante na simbolização das diferentes identidades no interior do universo juvenil.

Assim, entramos no terreno da multiplicação do real, da multiplicação de espaços e tempos desdobrando na quebra da sua uniformização e na 
reprodução dos multivíduos, que se articulam orientados pela busca de uma posição autônoma no quadro social. A cultura de consumo como uma cultura de comunicação visual, tende a produzir e reproduzir, para o autor, sinais bem reconhecíveis pelos multivíduos no estabelecimento de um modo diferente de estar no mundo.

O estar-junto passa a constituir a função agregadora que reconstrói a representação em tomo do requestionamento do corpo social no patrocínio da participação pública do que antes parecia ser negado. A referência a Durkheim e sua noção de consciência coletiva faz-se, de acordo com Michel Maffesoli, a chave necessária para compreendermos perfeitamente o tecido social contemporâneo e suas diversas efervescências efetuadas em tomo ou a partir de sentimentos, de emoções, de imagens, de símbolos suscitando a autonomia do ideal coletivo através de leis que lhes são próprias. A partilha em torno da musicalidade do rap gera a relação de revestimento que favorece a uma comunhão.

Partindo do princípio de que estamos num mundo tecnológico não mais comprometido a nenhuma esfera do social, frente a um enorme desenvolvimento de produção, mercados de consumo, vê-se a necessidade do reconhecimento do direito de cada um em sua singularidade na combinação da participação no mundo globalizado.

É preciso que reencontremos o sentido de nossa criatividade ao invés de sentirmos dominados pela técnica, pelas armas, pelo mercado. Cabe ressaltar que novos olhares sobre os entrelaçamentos do global e do local vem desmentindo a idéia anterior da fatalidade da monocultura. Numa perspectiva, diversos teóricos vem retomando a crítica do discurso concebida na intensificação da circulação dos fluxos culturais para demonstrar a existência inegável no qual a tendência à globalização da cultura não resulta na homogeneização do planeta, mas num mundo cada vez mais mestiço.
Atualmente, Massimo Canevacci (1996) desdobrando os conceitos de hibridação e mestiçagem engendra na explicação das combinações e reciclagens dos fluxos culturais internacionais pelas culturas locais. Outro antropólogo, o indiano Arjun Appadurai (Robertson, 1997), acredita que os instrumentos de homogeneização trazidos pela globalização (armamentos, técnicas publicitárias, a hegemonia de certos idiomas, a moda), ficam de fato absorvidos pelas economias políticas e culturais locais, unicamente para serem repatriados no tecido urbano como diálogos heterogêneos onde $o$ estado-nação se incumbe de um papel cada vez mais delicado.

Neste nível, afirma Canevacci, contra o poder linear da dialética histórica universalizante, o sincretismo - território marcado pelas travessias entre correntes extraterritoriais não só de etnias, mas também de estilos de vida, visões de mundo e sensibilidades estéticas - aparece como modelo onde os símbolos são vistos como estendidos sob profundas instâncias de simbolização, determinadas por tendências culturais múltiplas que fragmentam e remastigam todo o código.

Ao resgatar essa dimensão social da subjetividade propomos simplesmente evitar modelar o indivíduo com base em um único sujeito determinante, mas em diferentes circunstâncias do espaço híbrido dando margem ao aparecimento de um eu plural inquieto diante das divergentes multiplicidades interior/exterior numa resposta diante das limitações postas pela contemporaneidade. Afinal, as identidades não são fixas, mas se articulam com a estrutura das relações sociais que faz cada indivíduo ocupar múltiplas posições sociais através de identificações como de raça, gênero, classe, etnicidade, nível educacional, gostos, etc. As identificações são produzidas dentro de um campo ideológico nos quais os signos podem ser discursivamente re-articulados para conduzir a novos significados, 
elencando um corpo lingüístico capaz de articular uma pluralidade de praticas sociais que intersectam os indivíduos nelas afiliados.

$\mathrm{Na}$ narrativa do Rap Nacional, podemos encontrar um espaço dividido a partir de duas construções identitárias: o mundo do mano e o mundo do boy, permeado por códigos morais em referência ao social.

De um modo geral, temos aqui:

Jovens que moram na periferia ou manos (geralmente são negros e pobres)

São molestados constantemente pela polícia; sentem-se subordinados, desprezados; são discriminados pela forma como se vestem; são vistos como favelados e, por conseqüência, criminosos; são humildes; não são individualistas; são simples; espertos; valentes; são solidários; são companheiros.

Jovens que não moram na periferia ou playboys (geralmente são considerados como sendo ricos e brancos)

Geralmente são tratados, na narrativa do rap, por diminutivos no sentido pejorativo; são vistos como covardes e arrogantes; são aqueles que ostentam futilidades; são alienados do mundo que os cercam; são indiferentes; não são incomodados pela polícia; acham que podem tudo; possuem carros importados; não trabalham; acham-se superiores, melhores que os outros; individualistas; medrosos; não são solidários, nem companheiros; orgulhosos; podem consumir tudo o querem; desconhecem as dificuldades da pobreza; tem poder; protegido pela sociedade/impunidade; tem facilmente tudo na vida.

A adoção ao valor do outro, o "boy" gera um estado de despertencimento dos valores vigentes no mundo do mano.

\section{“HEY BOY”}

Hey boy o que você está fazendo aqui

Meu bairro não é seu lugar $E$ você vai se ferir

Você não sabe onde está

Caiu num ninho de cobra

E eu acho que vai ter que se explicar

Pra sair não vai ser fácil

A vida aqui é dura

Dura é a lei do mais forte

Onde a miséria não tem cura

E o remédio mais provável é a morte Continuar vivo é uma batalha

Isso é se eu não cometer falha

E se eu não fosse esperto

Tiravam tudo de mim

Arrancavam minha pele

Minha vida enfim

Tenho que me desdobrar

Pra não puxarem meu tapete

E estar sempre quente

Pra não ser surpreendido de repente

$$
\text { (...) }
$$

A pouca grana que eu tenho

Não dá pro próprio consumo

$$
\text { (...) }
$$

A solução é roubar

E seus pais acham que a cadeia é nosso lugar

O sistema é a causa

E nós somos a conseqüência...

Com nossa vida ninguém se importa

E ainda querem que sejamos patriotas...".

(Racionais MC's, Raio X Brasil, Zambia, 1993)

Aqui as comunidades imaginadas de manos e boys enquanto existência individual e social de configurações múltiplas representa os novos agrupamentos inseridos numa multiplicidade de espaços e tempos prestes a desdobrar na quebra da sua uniformização. Em todo o caso, os objetos simbólicos como a música rap, a vestimenta, a linguagem pode servir nesses grupos como mecanismos através dos quais a identidade passa a ser definida.

$\mathrm{Na}$ verdade, a noção de estilo de vida conota uma forma de autoexpressão e uma consciência de si 
estilizada, a tendência no qual o indivíduo reage ao nivelamento social (Featherstone, 1995). O Rap Nacional além de marcar sua importância na contestação voltada à problemática urbana sugere um novo espaço de reflexão e denúncia reivindicando para si espaços de sociabilidades nos quais os indivíduos, impulsionados por interesses diversos se soldam numa unidade distintiva dentro do corpo social.

A definição desses sujeitos se dá mais por aquilo que se diz deles na narrativa do rap, ocorrendo a partir daí um conjunto de controle do próprio discurso. E é por adotar os valores dos boys que o mano aos poucos perde o controle da sua própria definição de identidade, o abandono das origens e do projeto histórico de política cultural. A sociedade é assim considerada como violenta, desigual e injusta. A idéia de uma realidade é construída pela experiência cotidiana e o tipo de conhecimento do qual a mídia é portadora é vista como pouco confiável. Ao mesmo tempo em que os rappers atacam a mídia - nas músicas, nos discursos durante os shows e no dia a dia - eles precisam dela como canal de divulgação de sua arte e de suas idéias (Santos, 2002).

O rap tenta retratar uma realidade particular tal de onde estão os rappers, de acordo com o contexto sócio-espacial em que se vive e com a visão de mundo que se tem. A autenticidade refere ao "real" Rap Nacional aquele cuja construção musical é percebida como tendo uma direta conexão com o social expressado por uma comunidade de manos.

A ruptura instalada no discurso dos rappers enquanto estratégia de resistência ao que não é comum encaixa-se perfeitamente a um estado permanente de luta, de controle de território e pela expulsão do outro caracterizado na figura do boy - visto como normalizador dos poderes controladores da vida.

A globalização dessa forma vernacular, como tem chamado Paul Gilroy (1993), tem expressado os processos de mudança altamente contraditórios e desiguais. Um processo complexo que atravessa as mais diversas áreas da vida social, um vasto e intenso campo de conflitos entre grupos sociais, estados e interesses hegemônicos, por outro lado, e grupos sociais, estados e interesses subalternos, por outro. Nesse contexto, os meios de comunicação eletrônicos, especialmente a televisão tem sido um dos grandes temas do debate. O antropólogo indiano Arjun Appadurai (Santos, 2002) salienta que os media eletrônicos, longe de serem o ópio do povo, são processados por indivíduos e grupos de uma maneira ativa, num campo fértil onde as diferenças, os contrastes e as comparações se fazem presentes. Afinal, cabe aqui ao pesquisador a tarefa de decodificar o discurso gerando o contra-discurso que vai enunciar o que se encontra ainda oculto lidando sempre com a surpresa, o inesperado na dissolução do discurso comum.

Centralizar o sujeito através de suas práticas e representações pelas quais se relaciona e negocia com a sociedade, com a cultura e com os acontecimentos, significa dizer que o cotidiano não é só vivido, toma-se, sim objeto de interrogação e de debate, ou seja, é um espaço de reflexão e uma semente promotora de superações, das representações sociais. O mérito da constituição do campo da sociologia do cotidiano se dá em razão de o mesmo demonstrar a possibilidade de estabelecer ligações entre os grandes dispositivos sociais e os que regulam a vida cotidiana, bem como em resgatar o reaparecimento do sujeito face às estruturas, aos sistemas e ao instituído no vivido.

A vida cotidiana é, antes de tudo, um produto histórico. Ela se vincula e possui uma relação de estreiteza aos movimentos de rupturas e continuidades com modalidades organizativas de existência social. É um espaço estratégico de usos e táticas, de desvios, de tecnologias disseminadas (arte de falar, de falar, de silenciar, de registrar...). 
Os processos de socialização abrem múltiplas vias em direção a abordagem crítica do cotidiano, cujas interações buscam constantemente novos espaços onde a ação, reação e as estratégias dos atores em relação ao sistema social representam manifestações de sujeitos ativos no desenrolar dos conflitos e, não na realização de uma ação nos moldes parsonianos cuja finalidade está na manutenção de modelos de controle e objetivação da estabilidade e reprodução de valores normativos (Lefebvre, 1972; 1991). O sistema de ação dessas agremiações juvenis ultrapassa a função parsoniana, agregadora e integradora de papéis institucionados, de valores instituídos.

Dai a importância dada às interações focalizadas enquanto ritos de quebra com o estado de permanência de uma moral ou norma social e o estabelecimento de uma nova alternativa cujo indivíduo se desfaz enquanto pessoa (focalizado em papéis sociais), para decidir livremente sua ação no tempo e espaço na promoção das orientações dos projetos e processos vitais em suas trajetórias.

O interacionismo simbólico parte do pressuposto que os significados sociais são produzidos nas circunstâncias interatuantes dos atores. Segundo Erving Goffman (1970), os imponderáveis da vida real aparecem, estruturam-se e dinamizamse no encontro social, dando ênfase aos desejos individuais de manipular a apresentação do eu em relação aos papéis socialmente estruturados. Aqui, a interpretação da realidade social é feita através dos olhos do ator; realidade essa fundada em ações espontâneas, propiciando ao sujeito a competência e a defesa para atuar nos espaços interativos. Os microssistemas goffmianos são unidades que se constroem e se destroem em cujo interior os atores lutam e cooperam para estabelecer um sentido imediato do mundo social.

Sobre os papéis sociais, Agnes Heller (1985) explicita que, apesar de as funções de tipo "papel” serem condicionadas pelo conjunto da sociedade, o ser humano é mais do que seu papel ou conjunto dos seus papéis, porque eles jamais esgotam $o$ comportamento humano em sua totalidade.

Neste cenário, a vida pública existe precisamente para enfrentar questões de interesse coletivo que não podem ser resolvidas através de caminhos que contêm apenas verdades singulares, radicadas em interesses privados. Ela envolve e constrói mecanismos que devem dar conta da diversidade que nela se expressa. Dai a importância do pertencer, enquanto sujeito da ação coletiva e produtora de poder, entendido aqui como um recurso gerado pela habilidade dos membros de uma comunidade de estabelecerem uma discussão e eventualmente concordarem sobre qual o caminho a seguir (Sousa, 1998). Além do mais, o espaço público é o espaço de pertencimento que assegura as bases da relação dialógica, já que sua realidade é plural, ou seja, depende da presença da multiplicidade contida em perspectivas diferentes.

A despeito disso vemos em Jürgen Habermas (1984), a definição de esfera pública como sendo o espaço de livre acesso onde cidadãos se encontram para debater e racionalmente desenvolver argumentos sobre questões da vida comum. Paralelamente, é no ensaio de Hannah Arendth intitulado "A condição humana" (1999) que a esfera pública nos surge como pertencente e comum a todos. O espaço público conduz à produção da permanência e da história, na medida em que permite o ciclo de vida de cada pessoa ser transcendido. Ao radicar a esfera pública na condição humana da pluralidade, ela chama nossa atenção para a necessidade de reconhecer a multiplicidade de lógicas sociais que caracterizam a existência humana.

A esfera ou espaço público é o âmbito social no qual são debatidos temas relativos à coletividade onde se coloca em jogo o agir comunicacional, ou seja, espaço negociado-mediado 
onde se busca mais as mediações do que propriamente as determinações da estrutura social. Vale destacar, contudo, que o autor chamará de "comunicativas" às interações nas quais as pessoas envolvidas se põem de acordo para coordenar seus planos de ação, o acordo alcançado em cada caso medindo-se pelo reconhecimento intersubjetivo das pretensões de validez. No agir comunicativo os participantes tentam ter clareza sobre um interesse comum; ao negociar um compromisso, eles tentam chegar a um equilíbrio entre interesses particulares e antagônicos (Habermas, 1989).

A teoria da ação comunicativa reforça o lugar do homem como ator racional pela comunicação, lugar estratégico para uma ação que possibilitaria a busca da racionalidade na vida social baseado nos resultados da práxis humana. Na medida em que o homem cria a realidade humana e se comporta antes de tudo como ser prático, na condução do vivido para que tenha um sentido pessoal. Aliás, a comunicação não é um produto, mas um processo de troca simbólica generalizada, processo de que se alimenta a sociabilidade que gera os laços sociais que estabelecemos com os outros, sobrepondo-se às relações naturais que estabelecemos com o meio ambiente.

A comunicação é uma relação fundamentalmente intersubjetiva; enraíza-se na experiência particular e singular dos interlocutores, fazendo apelo tanto á experiência individual como á experiência coletiva que entendem por em comum (Rodrigues, 1990). Assim, a comunicação processa-se em função das escolhas que, em cada momento, fazemos de entre os conhecimentos, os sentimentos, os fatos e os dados possíveis, tendo em conta a nossa experiência, os nossos projetos e a nossa história singular.

Portanto, a importância de uma comunidade imaginada segue daí: ela evidencia um "nós" necessário para constituição de cada ser humano individual, processo que dá testemunho ao fato de que vidas individuais não se formam apenas de dentro das estruturas burocráticas institucionais, mas principalmente de fora, das arenas interacionais, dos espaços públicos de argumentação. A esfera da visibilidade ou esfera pública, responde as demandas de sociabilidade e comunicação. Processo público de debate, negociações argumentativas relativas ao bem comum. Podemos dizer que estamos formando uma metrópole comunicacional.

Nesta perspectiva, a identidade é referência, é o ponto original relativamente ao qual se define a diferença. A afirmação da identidade e a marcação da diferença implicam sempre, as operações de poder, de incluir e de excluir, significa demarcar fronteiras, significa fazer distinções entre "nós" e "eles".

Por esse prisma, cada um dos atores enquanto espectadores desempenham em seus trajetos cotidianos papéis que se mostram inseparáveis do espetáculo que demarcam para si. Afinal, o público, num autêntico sujeito de enunciação, se arroga no direito e até no dever de informar e ser informado, situando com isso a sua categoria do juízo crítico em oposição às modalidades enfocadas no sistema social.

\section{Bibliografia do Artigo}

ANDRADE, Elaine Nunes de (Org.). Hip-hop: movimento negro juvenil. In: Rap e Educação - Rap é Educação. São Paulo: Summus, 1999.

ARENDT, Hannah. A condição humana. Tradução de Roberto Raposo. Rio de Janeiro: Forense Universitária, 1999.

BAUDRILLARD, Jean. A sociedade de consumo. Tradução de Artur Morao. Rio de Janeiro: Elfos, 1995. (Série Ciência \& Sociedade; 3). 
BAUMAN, Zygmunt. O mal estar da pós-modernidade. Tradução de Mauro Gama, Cláudia Martinelli Gama. Rio de Janeiro: Jorge Zahar Editor, 1998.

BRAKE, Michael. Comparative youth culture: the sociology of youth cultures and youth subcultures in America, Britain, and Canada. New York: Routledge, 1985.

CALDAS, Waldenyr. Temas da cultura de massa: música, futebol, consumo. São Paulo: Arte \& Ciência Villipress, 2001.

CALDEIRA, Teresa Pires do Rio. Cidade de muros: crime, segregação e cidadania em São Paulo. Tradução de Frank Oliveira, Henrique Monteiro. São Paulo: Editora 34/EDUSP, 2000.

CANCLINI, Néstor Garcia. Consumidores e Cidadãos: conflitos multiculturais da globalização. Tradução de Maurício Santana Dias, Javier Rapp. 4. ed. Rio de Janeiro: Editora UFRJ, 1999.

CANEVACCI, Massimo. Sincretismos. Uma exploração das hibridações culturais. Tradução de Roberta Barni. São Paulo: Studio Nobel: Instituto Cultural Ítalo Brasileiro - Istituto italiano di Cultura, 1996.

FEATHERSTONE, Mike. Cultura de consumo e pós-modernismo. Tradução de Julio Assis Simões. São Paulo: Studio Nobel, 1995. (Série Megalopolis).

GILROY, Paul. The Black Atlantic: modernity and double consciouness. Cambridge, Mass.: Harvard University Press, 1993.

GOFFMAN, Erving. Ritual de la interacción. Buenos Aires: Editorial Tieempo Contemporáneo, 1970. (Biblioteca de Ciências Sociales).

HABERMAS, Jürgen. Consciência moral e agir comunicativo. Tradução de Guido Antonio de Almeida. Rio de Janeiro: Tempo Brasileiro, 1989. (Biblioteca Tempo universitário Estudos Alemães).

. Mudança estrutural na esfera pública: investigação quanto a uma categoria da sociedade burguesa. Rio de Janeiro: Tempo Brasileiro, 1984. (Biblioteca Tempo Universitário)

HALL, Stuart. A identidade cultural na pós-modernidade. Tradução de Tomaz Tadeu da Silva, Guacira Lopes Louro. 4. ed. Rio de Janeiro: DP\&A, 2000.

HELlER, Agnes. Cotidiano e história. Tradução de Carlos Nelson Coutinho, Leandro Konder. 2. ed. Rio de Janeiro: Paz e Terra, 1985.

HEBDIGE, Dick. Subculture: the meaning of style. London, New York: Routledge, 1988.

LEFEBVRE, Henri. La vida cotidiana en el mundo moderno. Madrid: Alianza, 1972.

O direito a cidade. Tradução de Eduardo Rubens Frias.

São Paulo: Moraes, 1991. 
MAFFESOLI, Michel. No fundo das aparências. Tradução de Bertha Halpern Gurovitz. 2. ed. Petrópolis: Vozes, 1999.

MARTINS, José de Souza. A sociabilidade do homem simples: cotidiano e história na modernidade anômala. São Paulo: Hucitec, 2000. (Coleção Ciências Sociais).

ROBERTSON, Roland. Social theory, cultural relativity and the problem of globality. In: KING, Anthony D. (Org.). Culture, globalization, and the world-system: contemporary condition for the representation of identity. Minneapolis, Minn.: University of Minnesota Press, 1997.

RODRIGUES, Adriano Duarte. Estratégias da comunicação: questão comunicacional e formas de sociabilidade. Lisboa: Editorial Presença, 1990. (Biblioteca de textos universitários).

ROSE, Tricia. Black Noise. Rap music and black culture in contemporany america. Hanover, London: University Press of New England/Wesleyan University Press, 1994.

SANTOS, Boaventura de Sousa (Org.). Os processos da globalização. In: A globalização e as Ciências Sociais. São Paulo: Cortez, 2002.

SANTOS, Rosana Aparecida Martins. O estilo que ninguém segura: Mano é Mano! Boy é Boy! Boy é Mano? Mano é Mano? Reflexão crítica sobre os processos de sociabilidade entre o público juvenil na cidade de São Paulo na identificação com a musicalidade do Rap Nacional. 2002. Dissertação (Mestrado em Ciências da Comunicação) - Escola de Comunicações e Artes de São Paulo, Universidade de São Paulo, São Paulo.

SILVA, José Carlos Gomes da. Rap na cidade de São Paulo: música, etnicidade e experiência urbana. 1998. Tese (Doutorado em Antropologia Social) Instituto de Filosofia e Ciências Humanas, Universidade Estadual de Campinas, Campinas.

SIMMEL, Georg. The philosophy of money. Tradução de Tom Bottomore, David Frisby. 2nd. London: Routledge, 1990.

SOUSA, Mauro Wilton de. Práticas de recepção mediática como práticas de pertencimento público. Novos Olhares, revista de estudos sobre prática de recepção a produtos mediáticos Dep. CTR/ECA-USP, ano II, n. 3, Iº sem. 1998.

TELLES, V. S.. Cidadania e pobreza. São Paulo: Editora 34, 2001. 